\title{
It's time for change with the management of non-specific chronic low back pain
}

\section{Peter O'Sullivan}

Low back pain (LBP) is the second greatest cause of disability in the USA. ${ }^{1}$ USA data supports that in spite of an enormous increase in the health resources spent on LBP disorders, the disability relating to them continues to increase. ${ }^{2}$ The management of LBP is underpinned by the exponential increase in the use of physical therapies, opiod medications, spinal injections as well as disc replacement and fusion surgery. ${ }^{2}$ This is maintained by the underlying belief that LBP is fundamentally a patho-anatomical disorder and should be treated within a biomedical model. ${ }^{1}$ This is in spite of calls over a number of years to adopt a bio-psycho-social approach, and evidence that only $8-15 \%$ of patients with LBP have an identified patho-anatomical diagnosis, resulting in the majority being diagnosed as having non-specific LBP. ${ }^{3}$ Of this population, a small but significant group becomes chronic and disabled, labelled non-specific chronic low back pain (NSCLBP), consuming a disproportionate amount of healthcare resources. ${ }^{4}$

1. Over the past decade, the traditional biomedical view of LBP has been greatly challenged. This is a result of:the failure of simplistic singledimensional therapies to show large effects in patients with NSCLBP ${ }^{5-8}$;

2. the results of clinical trials testing commonly prescribed interventions demonstrating that no management approaches are clearly superior ${ }^{5-7}$;

3. the stories of NSCLBP patients relating their own ongoing pain experiences of multiple failed treatments, conflicting diagnoses, lost hope and ongoing suffering ${ }^{10}$;

4. the indisputable evidence supporting the multidimensional nature of NSCLBP as a disorder, where disability levels are more closely associated with cognitive and behavioural

Correspondence to Professor Peter O'Sullivan, Professor/Specialist Musculoskeletal Physiotherapist, Curtin University, GPO Box U1987, Perth, WA 6845, Australia; p.osullivan@curtin.edu.au aspects of pain rather than sensory and biomedical ones ${ }^{11}{ }^{12}$;

5. positive outcomes in randomised controlled trials (RCTs) are best predicted by changes in psychological distress, fear avoidance beliefs, selfefficacy in controlling pain and coping strategies ${ }^{13} 14$;

6. the evidence supporting the broad subgrouping of NSCLBP disorders on the basis of neuro-physiological, ${ }^{15} 16$ cognitive, ${ }^{17}$ physical factors ${ }^{18}$ and lifestyle behaviours. ${ }^{19} 20$

Underlying primary healthcare clinical practice has been simplistic biomechanical and structural models of LBP and pelvic girdle pain (PGP), which focus on structural diagnoses such as spinal and pelvic 'instability'. 2122 These have been based on a belief that LBP and PGP is a result of structural (ie, degenerative), biomechani$\mathrm{cal}$ and motor control deficits resulting in segmental or regional 'instability' of the lumbo-pelvic region. ${ }^{21-24}$ It is now clear that there is little evidence (basic science and outcome studies) to support the view that 'instability' underpins the basis of disabling NSCLBP. There are no studies that demonstrate a clear relationship between spinal or pelvic mobility, degenerative processes, pain and disability. ${ }^{25} 26$ Similarly, common patho-anatomical findings such as degenerative disc disease, annular tears, fissures, facet joint arthrosis and disc bulges have been found not to be predictive of future LBP. ${ }^{26}$ This highlights the limitation of radiological imaging and spinal structure to provide clear meaning to people's experience of pain. Rather, factors such as depression, ${ }^{26} 27$ stress, cognitive and physical behaviours and lifestyle factors are more predictive of future LBP episodes. $^{1120}$

Yet in spite of this evidence, patients with disabling NSCLBP disorders continue to be provided with biomedical diagnoses and on the basis of these beliefs, people are prescribed with stabilising exercises, pelvic belts, supportive vests, spinal injections or even stabilisation surgery. ${ }^{1} 22328$ These 'magic bullet' approaches, for some, may in fact have the potential to drive fear, abnormal body focus and reinforce pain-related movement and avoidance behaviours, hypervigilance, catastrophising, pain and disability fuelling the vicious cycle of pain. ${ }^{29}$

Diagnostic labels such as 'instability' should be reserved solely for 'unstable fractures' and 'unstable spondylolisthesis'. ${ }^{30}$ The application of this diagnostic label to NSCLBP and PGP disorders is both inaccurate and potentially detrimental. ${ }^{21} 2931$ This 'belief system', which I once advocated, has resulted in the development of an educational and management industry aimed at enhancing spinal stability for the prevention and treatment of NSCLBP, influencing the practice of physiotherapy, allied health as well as sports rehabilitation and training industries across the world. ${ }^{28} 32$ This approach commonly instructs patients to contract their 'stabilising' muscles (pelvic floor and transverse abdominal wall and lumbar multifidus) prior to spinal loading and during movement. ${ }^{6} 92333$ In sports and gym rehabilitation settings, patients are frequently instructed to brace their abdominal wall and back muscles, to create more spinal 'stability' with the belief that 'more stability is better'.

Yet these management approaches have not arrested the growing disability associated with NSCLBP. ${ }^{2}$ Although there is evidence for the efficacy of stabilising exercise for NSCLBP, 34 a number of high-quality RCTs have demonstrated that specific spinal stabilising exercises for NSCLBP are not superior to other conservative approaches 693536 , they have small effect sizes ${ }^{37}$ and they are only marginally better than placebo treatment consisting of detuned shortwave and ultrasound. ${ }^{33}$ Yet the benefits of this approach continue to be exclusively promoted, in spite of mounting scientific evidence that questions the underlying basis of this clinical belief system. This includes evidence that the motor control characteristics of non-specific low back pain (NSLBP) and NSCLBP commonly lie in findings of:

1. increased co-contraction (stability) of trunk muscles ${ }^{38} 39$ and guarded spinal movement ${ }^{40}$;

2. hyperactivity of trunk muscles (including muscles such as erector spinae, lumbar multifidus, pelvic floor and transverse abdominal wall) in NSCLBP and PGP disorders ${ }^{18} 41$ 42;

3. an inability of the back muscles to $\operatorname{relax}^{18}{ }^{40}$;

4. a tendency for earlier onsets of the antero-lateral abdominal wall muscles during rapid arm movements rather than timing delays ${ }^{43}$; 
5. in some cases, trunk muscle hypertrophy in muscles such as lumbar multifidus $^{44}$ and quadratus lumborum ${ }^{45}$ have been documented in LBP sport populations.

Further to this, there is evidence for:

1. a lack of association between muscle density (degeneration) of lumbar multifudus and LBP in a recent large population study ${ }^{46}$;

2. a lack of association between changes in transversus abdominus muscle timing $^{47}$ and lumbar multifidus cross-sectional area ${ }^{13}$ as a predictor of positive outcomes (disability levels) in RCTs.

This body of research challenges current practice and beliefs and is a counter view to previous literature. Some of the apparent conflict within the literature appears to have arisen where the results of studies with small sample sizes, investigating subjects with recurrent $\mathrm{LBP}^{48}{ }^{49}$, have been extrapolated to the broad NSCLBP population without the results of these studies being reproduced in these populations or in larger groups.

The physiotherapy, manual therapy and medical professions have long focused on trying to find the magic 'technique', 'muscle', 'injection' or 'surgical technique' required to solve the problem of NSCLBP and PGP disorders. This reductionist approach to dealing with complex disorders in a simplistic manner clearly hasn't delivered for our patients ${ }^{50}$ and contradicts current knowledge that NSCLBP should be considered within a multidimensional bio-psycho-social framework. In fact, it has been proposed that single-dimensional approaches may in fact exacerbate chronic disorders reinforcing a cumulative feedback loop. ${ }^{29}$

In response to the calls to manage NSCLBP from a bio-psycho-social perspective, a number of RCTs have tested cognitive behavioural approaches to more effectively manage the disorder. Yet systematic reviews of these approaches have failed to demonstrate greater efficacy than other active conservative approaches in managing NSCLBP. ${ }^{51}$ Possible reasons for this failure may relate to the lack of patient-centred and targeted management $t^{52}$ as well as a failure to address other dimensions such as neuro-physiological factors and maladaptive lifestyle and movement behaviours known to be associated with NSCLBP disorders. ${ }^{18} 2030$

There is strong evidence that NSCLBP disorders are associated with a complex combination of physical behavioural, lifestyle, neuro-physiological (peripheral and central nervous system changes), psychological/cognitive and social factors. ${ }^{12} 2030$ These factors together have the potential to promote maladaptive cognitive behaviours (negative beliefs, fear, avoidance, catastrophising, hypervigilance), ${ }^{53}$ pain behaviours (pain communicative and avoidant behaviours) ${ }^{54}$ and movement behaviours, ${ }^{30}$ setting up a vicious cycle of pain sensitisation and reinforcing disability. Changes in immune and neuroendocrine function linked to altered stress responsiveness coupled with activation of the pain neuro-matrix in the brain may result in tissue hyperalgesia and altered neuro-muscular responses. ${ }^{11}$ It is thought that these processes are mediated by environmental/genetic interactions. ${ }^{55}$

The balance and contribution of these different factors will likely vary for each individual. For example, it is known that not all NSCLBP disorders are associated with significant psychosocial factors. ${ }^{17} 56$ However, there is strong evidence that disability and factors such as sick leave are best predicted by factors such as negative back pain beliefs, fear and distress. ${ }^{17} 57$ Futhermore, psychological factors such as fear and catastrophising commonly associated with disabling pain have lifestyle, physical, neuro-muscular ${ }^{40}$ as well as neuro-biological consequences, highlighting that the mind and the body are inextricably linked. ${ }^{11}$

There is also growing evidence that NSCLBP disorders can be broadly categorised or subgrouped based on different psychosocial/coping behaviours, ${ }^{17} \quad 58 \quad 59$ neuro-physiological characteristics, ${ }^{15} 56$ pain behaviours ${ }^{54}$ and movement behaviours, ${ }^{18} 30$ providing greater potential for targeting of multidimensional interventions. ${ }^{60}$ These broad subgroups, rather than being rigid entities which are characterised by prediction rules, ${ }^{61}$ may provide a framework for the clinician to tailor management to patients in a more targeted person-centred multidimensional manner. 305859

There is emerging evidence to support this view that patient-centred multidimensional targeted behavioural approaches have greater efficacy than current practice for the management of NSCLBP disorders in primary care settings. Asenlöf et a ${ }^{62} 63$ compared individually tailored treatment targeting activity levels, motor behaviour and cognitions, demonstrating superior outcomes to exercise therapy. A patientcentred multidimensional behavioural approach called 'classification-based cognitive functional therapy' that targets maladaptive cognitive, lifestyle, pain and movement behaviours was more effective (greater effect sizes) than manual therapy and exercise for localised NSCLBP. ${ }^{64}$ Hill et al ${ }^{65}$ employed a patient-centred stratification approach to target physiotherapy treatment based on psychosocial risk profile, demonstrating superior outcomes and cost saving over standard physiotherapy care. Further research into this patientcentred multidimensional approach is clearly required but recent evidence is encouraging for improved outcomes.

Other behavioural therapies such as mindfulness meditation, ${ }^{66}$ acceptance and commitment therapy, ${ }^{67}$ brain-directed therapies ${ }^{68} 69$ and targeted medical management ${ }^{70}$ hold hope for the multidisciplinary management of some of the highly complex and disabling central nervous system pain disorders.

In spite of this emerging evidence, recent research highlights that health professionals dealing with LBP disorders have difficulty accurately identifying psycho-social risk in their patients, limiting their capacity to target management. ${ }^{71}$ It appears that specific training in behavioural aspects of a patients presentation is required to enable health professionals to identify psycho-social risk factors and maladaptive movement behaviours from a clinical examination. ${ }^{72}$ There is also growing evidence to support the critical role that the quality of the therapeutic relationship plays in the management of pain disorders. ${ }^{73}$ Practitioner-related factors such as communication skills, empathy, level of confidence and beliefs have an important influence on patient outcomes and compliance to treatment. ${ }^{74}$ Conversely, patient beliefs and expectations also have a profound influence on health disorder outcomes. ${ }^{75}$

With all this in mind, the challenges for the future in more effectively dealing with NSCLBP disorders are likely to involve primary healthcare providers shifting rigidly held biomedical beliefs and developing greater skills and knowledge across a number of domains. These skills are likely to include:

1. Greater understanding of the complex multidimensional nature of NSCLBP.

2. Developing diagnostic skills to clearly differentiate specific pathology as a driver of pain from NSLBP disorders.

3. Develop more effective communication skills utilising empathy, reflective questioning and motivational interviewing techniques in order to listen to the patients' story and explore their pain beliefs, fears, coping strategies, life stresses, psycho-social factors, pain behaviour, impairments and goals. This allows 
for the development of an effective therapeutic relationship and the accurate interpretation of clinical information within a bio-psycho-social framework in order to identify the primary drivers of pain and disability. This in turn provides the capacity to clearly outline the vicious cycle of the disorder in a patient-centred way.

4. Identification of maladaptive cognitive behaviours (negative beliefs, stress responsiveness, provocative coping strategies, hypervigilance, fear, catastrophising, anxiety, depression etc).

5. Identifying neuro-physiological processes such as central and peripheral sensitisation.

6. The analysis and interpretation of pain communicative and avoidant behaviours $^{54}$ and movement and postural behaviours $^{30}$ in order to determine adaptive (protective) from maladaptive (provocative) behaviours. ${ }^{30}$

7. Synthesising and interpreting clinical information across multiple domains.

8. Developing multidimensional and flexible interventions that target maladaptive cognitive, lifestyle, pain and movement behaviours in an integrated manner.

9. Facilitation of behavioural change in patients by enhancing clinical skills such as empathy, motivation, support, creativity, goal setting, flexible person-centred functional rehabilitation programmes and clear feedback.

10. Developing clear multidisciplinary approaches to management where indicated.

11. Developing a broad framework for subgrouping of NSCLBP patients from a multidimensional perspective. $^{17} \quad 305258$ This will allow the broad categorisation of LBP disorders based on the presence of dominant psycho-social, neuro-physiological, lifestyle and movement behaviours that act as drivers for the disorder.

12. Adopting the routine use of screening tools in clinical practice in order to identify risk and targets for change to better direct management. ${ }^{6576}$

This approach will likely focus less on treating the structure or signs and symptoms of a disorder in NSCLBP disorders and more on targeting the different combinations of beliefs, cognitive, pain, lifestyle and movement behaviours that underlie and drive disorders. Implementation of this approach will require a paradigm shift in 'beliefs' of health professionals in terms of how we understand and deal with NSCLBP disorders. This will involve abandoning ineffective practices, learning new skills, adopting and integrating new approaches. This new knowledge and skill needs to be trained at undergraduate and graduate levels and promoted actively within the professions that deal with these disorders. ${ }^{77}$ There is also a mandate to educate the public in order to reinforce more positive back pain beliefs to reduce the burden for both individuals and society. ${ }^{78}$ This will invariably lead to health insurers abandoning the ongoing funding of non-efficacious treatment approaches.

Further research is clearly needed to better identify the underlying mechanisms associated with disabling NSCLBP disorders and their development across the lifespan. This will likely involve a greater understanding of genetic/environmental interactions associated with the development of the nervous system, tissue sensitisation and associated maladaptive behaviours, tracking from early life to adolescence and into adulthood. Developing a greater understanding of those people resilient to these disorders may also be illuminating. Early screening and targeted management of risk groups, based on the identification of the mechanisms that drive them, may aid in the prevention of pain chronicity and disability. Innovative multidimensional, patient-centred and targeted approaches to management for these complex disorders need to be further developed and adequately tested.

Characteristics such as hope, positive help seeking and adaptability are traits of resilience that we need to equip our patients with, who suffer with disabling NSCLBP. ${ }^{12}$ Adopting a positive multidimensional perspective of health that is person focused may allow us to view NSCLBP in a new light, providing hope for our patients and an environment for innovation, discovery and change.

Acknowledgements The author would like to acknowledge the support of Joao Paulo Caneiro in the preparation of this manuscript.

\section{Competing interests None.}

Provenance and peer review Not commissioned; externally peer reviewed.

Accepted 29 June 2011

Published Online First 4 August 2011

Br J Sports Med 2012;46:224-227.

doi:10.1136/bjsm.2010.081638

\section{REFERENCES}

1. Bagnall DL. Physiatry: what's the end game? PM R 2010;2:3-5.
2. Deyo RA, Mirza SK, Turner JA, et al. Overtreating chronic back pain: time to back off? J Am Board Fam Med 2009;22:62-8.

3. Waddell G. The Back Pain Revolution. Edinburgh: Churchill Livingstone 2004.

4. Croft PR, Macfarlane GJ, Papageorgiou AC, et al. Outcome of low back pain in general practice: a prospective study. BMJ 1998;316:1356-9.

5. Assendelft WJ, Morton SC, Yu El, et al. Spinal manipulative therapy for low back pain. Cochrane Database Syst Rev 2004;1:CD000447.

6. Ferreira ML, Ferreira PH, Latimer J, et al. Comparison of general exercise, motor control exercise and spinal manipulative therapy for chronic low back pain: a randomized trial. Pain 2007;131:31-7

7. Hayden JA, van Tulder MW, Tomlinson G. Systematic review: strategies for using exercise therapy to improve outcomes in chronic low back pain. Ann Intern Med 2005;142:776-85.

8. Ostelo RW, Van Tulder MW, Vlaeyen J, et al. Behavioural treatment for chronic low back pain. Cochrane Database Syst Rev 2005;1:CD002014.

9. Unsgaard-Tøndel M, Fladmark AM, Salvesen Ø, et al. Motor control exercises, sling exercises, and general exercises for patients with chronic low back pain: a randomized controlled trial with 1-year follow-up. Phys Ther 2010;90:1426-40.

10. Holloway I, Sofaer-Bennet B, Walker J. The transition from well person to 'pain afflicted' patient: the career of people with chronic back pain. IIIness Crisis Loss 2000;8:373-87.

11. Campbell CM, Edwards RR. Mind-body interactions in pain: the neurophysiology of anxious and catastrophic pain-related thoughts. Trans/ Res 2009;153:97-101.

12. Gatchel RJ, Peng YB, Peters ML, et al. The biopsychosocial approach to chronic pain: scientific advances and future directions. Psychol Bull 2007; 133:581-624.

13. Mannion AF, Junge A, Taimela S, et al. Active therapy for chronic low back pain: part 3. Factors influencing self-rated disability and its change following therapy. Spine 2001;26:920-9.

14. Woby SR, Urmston M, Watson PJ. Self-efficacy mediates the relation between pain-related fear and outcome in chronic low back pain patients. Eur J Pain 2007;11:711-18.

15. Woolf CJ, Bennett GJ, Doherty M, et al. Towards a mechanism-based classification of pain? Pain 1998;77:227-9.

16. Woolf CJ, Salter MW. Neuronal plasticity: increasing the gain in pain. Science 2000;288:1765-9.

17. Boersma K, Linton SJ. Psychological processes underlying the development of a chronic pain problem: a prospective study of the relationship between profiles of psychological variables in the fear-avoidance model and disability. Clin J Pain 2006;22:160-6.

18. Dankaerts W, O'Sullivan P, Burnett A, et al. Discriminating healthy controls and two clinical subgroups of nonspecific chronic low back pain patients using trunk muscle activation and lumbosacral kinematics of postures and movements: a statistical classification model. Spine 2009;34:1610-18.

19. Björck-van Dijken C, Fjellman-Wiklund A, Hildingsson C. Low back pain, lifestyle factors and physical activity: a population based-study. J Rehabil Med 2008;40:864-9.

20. Mitchell T, O'Sullivan PB, Burnett A, et al. Identification of modifiable personal factors that predict new-onset low back pain: a prospective study of female nursing students. Clin J Pain 2010;26:275-83.

21. Renckens CN. Between hysteria and quackery: some reflections on the Dutch epidemic of obstetric 'pelvic instability'. J Psychosom Obstet Gynaecol 2000;21:235-9. 
22. O'Sullivan PB. Lumbar segmental 'instability': clinical presentation and specific stabilizing exercise management. Man Ther 2000;5:2-12.

23. Richardson C, Hodges P, Hides J. Therapeutic Exercise for Lumbopelvic Stabilization - A Motor Control Approach for the Treatment and Prevention of Low Back Pain. 2nd edition. Churchill Livingstone, Edinburgh 2004.

24. Sahrmann S. Diagnosis and Treatment of Movement Impairment Syndromes. Mosby St Louis, Mo; London 2001.

25. Damen L, Buyruk HM, Güler-Uysal F, et al. Pelvic pain during pregnancy is associated with asymmetric laxity of the sacroiliac joints. Acta Obstet Gynecol Scand 2001;80:1019-24.

26. Jarvik JG, Hollingworth W, Heagerty PJ, et al. Three-year incidence of low back pain in an initially asymptomatic cohort: clinical and imaging risk factors. Spine 2005;30:1541-8.

27. Carroll LJ, Cassidy JD, Côté P. Depression as a risk factor for onset of an episode of troublesome neck and low back pain. Pain 2004;107:134-9.

28. Comerford MJ. Core stability - priorities in the management of the athlete. Sport Ex Med 2004:22:15-22.

29. Brown CA. Mazes, conflict, and paradox: tools for understanding chronic pain. Pain Pract 2009;9:235-43.

30. O'Sullivan P. Diagnosis and classification of chronic low back pain disorders: maladaptive movement and motor control impairments as underlying mechanism. Man Ther 2005:10:242-55.

31. O'Sullivan PB, Beales DJ. Diagnosis and classification of pelvic girdle pain disorders - part 1: a mechanism based approach within a biopsychosocial framework. Man Ther 2007:12:86-97.

32. Cook J. Jumping on bandwagons: taking the right clinical message from research. Br J Sports Med 2008:4:941-4.

33. Costa L0, Maher CG, Latimer J, et al. Motor control exercise for chronic low back pain: a randomized placebo-controlled trial. Phys Ther 2009;89:1275-86.

34. Ferreira PH, Ferreira ML, Maher CG, et al. Specific stabilisation exercise for spinal and pelvic pain: a systematic review. Aust J Physiother 2006;52:79-88.

35. Critchley DJ, Ratcliffe J, Noonan S, et al. Effectiveness and cost-effectiveness of three types of physiotherapy used to reduce chronic low back pain disability: a pragmatic randomized trial with economic evaluation. Spine 2007;32:1474-81

36. Koumantakis GA, Watson PJ, Oldham JA. Supplementation of general endurance exercise with stabilisation training versus general exercise only. Physiological and functional outcomes of a randomised controlled trial of patients with recurrent low back pain. Clin Biomech (Bristol, Avon) 2005;20:474-82

37. Dworkin RH, Turk DC, McDermott MP, et al. Interpreting the clinical importance of group differences in chronic pain clinical trials: IMMPACT recommendations. Pain 2009;146:238-44.

38. Hodges $\mathbf{P}$, van den Hoorn W, Dawson A, et al. Changes in the mechanical properties of the trunk in low back pain may be associated with recurrence. J Biomech 2009;42:61-6.

39. van Dieën JH, Selen LP, Cholewicki J. Trunk muscle activation in low-back pain patients, an analysis of the literature. J Electromyogr Kinesiol 2003;13:333-51.

40. Geisser ME, Haig AJ, Wallbom AS, et al. Painrelated fear, lumbar flexion, and dynamic EMG among persons with chronic musculoskeletal low back pain. Clin J Pain 2004;20:61-9.

41. Pool-Goudzwaard AL, Slieker ten Hove MC Vierhout ME, et al. Relations between pregnancy- related low back pain, pelvic floor activity and pelvic floor dysfunction. Int Urogynecol J Pelvic Floor Dysfunct 2005;16:468-74.

42. Dankaerts W, O'Sullivan P, Burnett A, et al. Altered patterns of superficial trunk muscle activation in non-specific chronic low back pain patients: the importance of sub-classifcation. Spine 2006;31:2017-23.

43. Gubler D, Mannion AF, Schenk P, et al. Ultrasound tissue Doppler imaging reveals no delay in abdominal muscle feed-forward activity during rapid arm movements in patients with chronic low back pain. Spine 2010;35:1506-13.

44. McGregor AH, Anderton L, Gedroyc WM. The trunk muscles of elite oarsmen. Br J Sports Med 2002;36:214-7.

45. Hides J, Stanton W, Freke M, et al. MRI study of the size, symmetry and function of the trunk muscles among elite cricketers with and without low back pain. Br J Sports Med 2008;42:809-13.

46. Kalichman L, Hodges P, Li L, et al. Changes in paraspinal muscles and their association with low back pain and spinal degeneration: CT study. Eur Spine J 2010;19:1136-44.

47. Oestergaard LG. Abdominal muscle onset after specified general exercises: a randomised controlled trial. Proceedings of 7th Interdisciplinary World Congress on Low Back and Pelvic Pain, 9-12 November, 2010, Los Angeles, CA, USA.

48. Hodges PW, Richardson CA. Inefficient muscular stabilization of the lumbar spine associated with low back pain. A motor control evaluation of transversus abdominis. Spine 1996;21:2640-50.

49. Hides JA, Jull GA, Richardson CA. Long-term effects of specific stabilizing exercises for first-episode low back pain. Spine 2001;26:E243-8.

50. Wand BM, O'Connell NE. Chronic non-specific low back pain - sub-groups or a single mechanism? BMC Musculoskelet Disord 2008;9:11.

51. Henschke N, Ostelo RWJG, van Tulder MW, et al. Behavioural treatment for chronic low-back pain. Cochrane Database Syst Rev 2010;7:CD002014.

52. Hill JC, Foster NE, Main CJ, et al. In response to: 'a randomized trial of behavioural physical therapy interventions for acute and sub-acute low back pain', by George SZ. Pain 2009;140:145-57.

53. Vlaeyen JW, Morley S. Cognitive-behavioral treatments for chronic pain: what works for whom? Clin J Pain 2005;21:1-8

54. Martel M0, Thibault P, Sullivan MJ. The persistence of pain behaviors in patients with chronic back pain is independent of pain and psychological factors. Pain 2010;151:330-6

55. Reichborn-Kjennerud T, Stoltenberg C, Tambs K, et al. Back-neck pain and symptoms of anxiety and depression: a population-based twin study. Psychol Med 2002;32:1009-20.

56. Dunn KM, Croft PR. Classification of low back pain in primary care: using 'bothersomeness' to identify the most severe cases. Spine 2005;30:1887-92.

57. Briggs AM, Jordan JE, Buchbinder R, et al. Health literacy and beliefs among a community cohort with and without chronic low back pain. Pain 2010;150:275-83.

58. Turk DC. The potential of treatment matching for subgroups of patients with chronic pain: lumping versus splitting. Clin J Pain 2005;21:44-55.

59. Hill JC, Dunn KM, Lewis M, et al. A primary care back pain screening tool: identifying patient subgroups for initial treatment. Arthritis Rheum 2008:59:632-41.

60. Simmonds MJ, Smeets RJ, Degenhardt B. Pain, mind, and movement: towards a sophisticated understanding and a tailored clinical approach. Clin J Pain 2010;26:737-8.

61. Childs JD, Fritz JM, Flynn TW, et al. A clinical prediction rule to identify patients with low back pain most likely to benefit from spinal manipulation: a validation study. Ann Intern Med 2004;141:920-8.

62. Asenlöf $\mathbf{P}$, Denison $\mathrm{E}$, Lindberg P. Individually tailored treatment targeting activity, motor behavior, and cognition reduces pain-related disability: a randomized controlled trial in patients with musculoskeletal pain. J Pain 2005;6:588-603.

63. Asenlöf $\mathbf{P}$, Denison E, Lindberg P. Long-term follow-up of tailored behavioural treatment and exercise based physical therapy in persistent musculoskeletal pain: a randomized controlled trial in primary care. Eur J Pain 2009:13:1080-8.

64. Fersum KV, O'Sullivan P, Kvale A, et al. Classification based cognitive functional therapy for the management of non-specific low back pain (NSLBP) - a randomized control trial. Melbourne International Forum XI, Primary Care Research on Low Back Pain, 15-18 March 2011, Melbourne, Victoria, Australia

65. Hill J, Dunn K, Lewis M, et al. A randomised trial of targeted treatment for low back pain compared with current best practice: the start back trial. Melbourne International Forum XI, Primary Care Research on Low Back Pain, 15-18 March 15-18 2011, Melbourne, Victoria, Australia.

66. McCracken LM, Gauntlett-Gilbert J, Vowles KE. The role of mindfulness in a contextual cognitivebehavioral analysis of chronic pain-related suffering and disability. Pain 2007;131:63-9.

67. Meredith P, Ownsworth T, Strong J. A review of the evidence linking adult attachment theory and chronic pain: presenting a conceptual model. Clin Psychol Rev 2008;28:407-29.

68. Moseley GL. Pain, brain imaging and physiotherapy - opportunity is knocking. Man Ther 2008;13:475-7.

69. Wand BM, Parkitny L, O'Connell NE, et al. Cortical changes in chronic low back pain: current state of the art and implications for clinical practice. Man Ther 2011;16:15-20.

70. Reichling DB, Levine JD. Critical role of nociceptor plasticity in chronic pain. Trends Neurosci 2009;32:611-18.

71. Hill JC, Vohora K, Dunn KM, et al. Comparing the STarT back screening tool's subgroup allocation of individual patients with that of independent clinical experts. Clin J Pain 2010;26:783-7.

72. Fersum KV, Kvale A, O'Sullivan P, et al. Interexaminer reliability of a classification system for patients with non-specific low back pain. Man Ther 2009;14:555-61.

73. Slade SC, Molloy E, Keating JL. People with non-specific chronic low back pain who have participated in exercise programs have preferences about exercise: a qualitative study. Aust J Physiother 2009:55:115-21

74. Hartman SE. Why do ineffective treatments seem helpful? A brief review. Chiropr Osteopat 2009;17:10.

75. Goubert L, Craig KD, Vervoort T, et al. Facing others in pain: the effects of empathy. Pain 2005;118:285-8.

76. Linton SJ, Boersma K. Early identification of patients at risk of developing a persistent back problem: the predictive validity of the Orebro Musculoskeletal Pain Questionnaire. Clin J Pain 2003;19:80-6.

77. Foster NE, Delitto A. Embedding psychosocial perspectives within clinical management of low back pain: integration of psychosocially informed management principles into physical therapist practice - challenges and opportunities. Phys Ther 2011;:91:790-803.

78. Buchbinder R, Pransky G, Hayden J. Recent advances in the evaluation and management of nonspecific low back pain and related disorders. Best Pract Res Clin Rheumatol 2010;24:147-53. 
BJSM

\section{It's time for change with the management of non-specific chronic low back pain}

Peter O'Sullivan

Br J Sports Med 2012 46: 224-227 originally published online August 4, 2011

doi: 10.1136/bjsm.2010.081638

Updated information and services can be found at:

http://bjsm.bmj.com/content/46/4/224.full.html

These include:

References This article cites 71 articles, 10 of which can be accessed free at: http://bjsm.bmj.com/content/46/4/224.full.html\#ref-list-1

Email alerting Receive free email alerts when new articles cite this article. Sign up in service the box at the top right corner of the online article.

Topic Articles on similar topics can be found in the following collections Collections

Notes

To request permissions go to:

http://group.bmj.com/group/rights-licensing/permissions

To order reprints go to:

http://journals.bmj.com/cgi/reprintform

To subscribe to BMJ go to:

http://group.bmj.com/subscribe/ 